\title{
Gene expression pattern of Treg and TCR VY subfamily $T$ cells before and after specific immunotherapy in allergic rhinitis
}

\author{
Rui Zheng ${ }^{1+}$, Xiuli Wu ${ }^{2+}$, Xuekun Huang ${ }^{1}$, Yulian Chen ${ }^{1}$, Qintai Yang ${ }^{1 *}$, Yangqiu Li ${ }^{2}$ and Gehua Zhang ${ }^{1}$
}

\begin{abstract}
Background: $T$ regulatory cell (Treg) plays a critical role in respiratory allergy and allergen-specific immunotherapy (SIT), and $\gamma \delta$ T cells might participate in mediating Treg quantity and/or function in some immunological diseases. To further characterize whether $\gamma \delta$ T cells could influence Treg in allergic rhinitis (AR) and SIT, we investigated the expression pattern of Treg's Foxp3 gene and $\gamma \delta T$ cell receptor (TCR) $V_{Y}$ subfamily genes in peripheral blood mononuclear cells (PBMCS) of AR patients before and after SIT.
\end{abstract}

Methods: Eighteen AR patients undergoing effective SIT with house dust mite extract for one year were recruited. Visual Analogue Scale (VAS) was applied to evaluate the severity. Immunofluorescence quantification analysis was performed to determine the serum specific lgE (slgE) content. Real-time PCR was used to detect the expression levels of Foxp3 and TCR $V_{Y}$ subfamilies. Ten healthy volunteers were recruited as the controls.

Results: Nasal uni-VAS score after SIT was significantly lower than that before SIT, while serum slgE content was similar before and after SIT. Expression levels of Foxp3 and TCR VY subfamilies in AR patients before treatment were significantly lower than those in healthy subjects. Expression levels of $\mathrm{V} Y \mathrm{l}$ and II were similar before and after SIT, while expression levels of Foxp3 and VYIII after SIT were significantly higher than those before. Before SIT, the significant positive correlation was observed between expression levels of Foxp3 and VYl, II, III, while negative correlation was observed between Foxp3, VYIII and VAS. After SIT, the significant positive correlation between expression levels of Foxp3 and VYllI and negative correlation between Foxp3, VYIII and VAS were observed.

Conclusions: Treg and $V_{Y}$ subfamily T cells were in a dynamic equilibrium in AR patients before and after effective immunotherapy for one year. The early improvement of symptoms following immunotherapy might be independent of the serum slgE content in AR patients, but associated with the reconstitution of T cell immunity.

Keywords: Allergic rhinitis, Specific immunotherapy, Foxp3, Treg, ү $\delta$ T cells

\section{Background}

Allergic Rhinitis (AR) is part of the systemic allergic disease, which involves the formation of specific IgE antibodies against innocuous environmental substances. Allergen-specific immunotherapy (SIT) is currently the only therapeutic choice to alter the natural course of AR and has gradually become the first-line treatment, yet its functional mechanism has not been fully elucidated. It

\footnotetext{
* Correspondence: yang.qt@163.com

${ }^{\dagger}$ Equal contributors

'Department of Otorhinolaryngology-Head and Neck Surgery, The Third Affiliated Hospital, SUN Yat-sen University, Guangzhou 510630, China
} Full list of author information is available at the end of the article has been reported that $\mathrm{T}$ regulatory cell (Treg) quantity and/or function were reduced in allergic diseases [1], and SIT could make the quantity rebound and/or the function recover [2]. Previous studies from others [3] and us [4] have found that CD4 $4^{-}{ }^{-} 8^{-} \gamma \delta \mathrm{T}$ cells predominantly expressed in mucous membrane participate in respiratory allergy. Various functional subsets of $\gamma \delta \mathrm{T}$ cells could promote or suppress allergic inflammation under different conditions, and clinical effectiveness of SIT was possibly related to the induction of inflammation suppression by the subsets of $\gamma \delta$ T cells [5]. It was confirmed in a recent study that $\gamma \delta \mathrm{T}$ cells could limit 
Treg quantity and inhibit its function by generating plenty of IL-17, thus promoting autoimmune inflammation [6]. However, the role of $\gamma \delta \mathrm{T}$ cells in allergic inflammation has not yet been reported. The aim of this study was to investigate the expression pattern of different $\gamma \delta$ T cell subfamilies (subsets) as well as their potential correlation with Treg in untreated AR and after early SIT by testing the expression levels of Foxp3 and TCR $\mathrm{V} \gamma \mathrm{I} \sim \mathrm{III}$ genes in AR patients before and after one-yearlong effective SIT.

\section{Methods}

\section{Sample collection}

The subjects of the study were 18 patients with moderate to severe persistent AR sensitized to house dust mites $(7$ males and 11 females; median age: 25 years, range: $6 \sim 38$ years). All patients were diagnosed based on ARIA guideline (Allergic Rhinitis and its Impact on Asthma; 2008 update [7]), and received SIT with standardized house dust mite extract (standardized immunotherapy protocol of the University of Copenhagen, Denmark) for 1 year at the Third Affiliated Hospital of Sun Yat-Sen University. The clinical characteristics of the patients were listed on Table 1. The therapy was effective based on the effective criteria [8]. Peripheral blood samples were obtained from the patients at the beginning of their immunotherapy and after one year's treatment. One month before SIT, all subjects were withheld from oral corticosteroids, antihistamines or

Table 1 Clinical characteristics of AR patients

\begin{tabular}{ccccc}
\hline Case number & Sex & Age (years) & $\begin{array}{c}\text { VAS score } \\
\text { before SIT }\end{array}$ & $\begin{array}{c}\text { VAS score } \\
\text { after SIT }\end{array}$ \\
\hline 1 & Female & 10 & 8.36 & 2.87 \\
2 & Male & 22 & 7.94 & 2.37 \\
3 & Male & 25 & 7.92 & 0.46 \\
4 & Female & 25 & 7.89 & 1.74 \\
5 & Female & 36 & 8.09 & 3.82 \\
6 & Male & 12 & 7.03 & 3.54 \\
7 & Female & 31 & 7.35 & 1.47 \\
8 & Male & 31 & 7.83 & 1.72 \\
9 & Female & 38 & 6.96 & 2.13 \\
10 & Female & 6 & 7.51 & 1.68 \\
11 & Female & 12 & 7.85 & 2.26 \\
12 & Female & 21 & 7.97 & 3.68 \\
13 & Male & 27 & 8.27 & 2.54 \\
14 & Female & 17 & 8.01 & 0.37 \\
15 & Female & 35 & 7.99 & 0.96 \\
16 & Male & 25 & 7.63 & 2.44 \\
17 & Male & 21 & 7.42 & 3.06 \\
18 & Female & 37 & 7.72 & 3.18 \\
\hline
\end{tabular}

immunotherapy. Ten healthy individuals with no symptom of any allergic diseases and negative serum sIgE served as the control group (4 males and 6 females; median age: 27.5 years, range: $16 \sim 40$ years). Serums were separated by low-speed centrifugation. The PBMCs were isolated using Ficoll-Hypaque gradient centrifugation method. RNA extraction and cDNA synthesis was performed according to the manufacturer's instructions [9]. All samples were obtained with written informed consent from the participants, and all of the procedures were conducted according to the guidelines of the Medical Ethics Committee of Health Bureau of China before study initiation.

\section{Visual analogue scale}

The severity of the nasal symptoms of 18 AR patients before and after immunotherapy was assessed according to Visual Analogue Scale (VAS) [10]. The global discomfort caused by AR during the previous week of the test was rated on a $0-10$ scale, 0 being no symptom, and 10 being the maximal severity of the symptom.

\section{Serum specific IgE detection}

The contents of serum specific $\operatorname{IgE}(\mathrm{sIgE})$ against the house-dust-mite allergen before and after SIT were detected using the automatic system of immunofluorescence quantitative analysis (UniCAP 100E; Pharmacia, Sweden).

\section{Real-time polymerase chain reaction for Foxp3 and TCR $\mathrm{V} Y \mathrm{I} \sim$ III subfamily genes}

Real-time polymerase chain reaction (PCR) was used to determine Foxp3 and TCR V VI III gene expression levels in the PBMCs from samples. Beta 2-microglobulin $\left(\beta_{2} \mathrm{M}\right)$ gene was used as an endogenous reference. The sequences of primers were listed in Table 2. PCR was performed as previously described [11,12]. In brief, $20 \mu \mathrm{l}$ PCR reaction mixture containing approximately $1 \mu \mathrm{L}$ of cDNA, $0.6 \mathrm{mmol} / \mathrm{L}$ of each primer, and $10 \mu \mathrm{l}$ of $2.5 \times$ Real Master Mix (Tiangen Biotech (Beijing) Co. Ltd., Beijing, China) was prepared. Amplification was carried out on the CFX96 ${ }^{\text {tm }}$ Real-Time PCR cycler (Bio-Rad,

Table 2 Sequences of primers used in real-time PCR

\begin{tabular}{ll}
\hline Primers & Sequences \\
\hline Foxp3-f & 5'-CTGACCAAGGCTTCATCTGTG-3' \\
Foxp3-b & 5'-ACTCTGGGAATGTGCTGTTC-3' \\
$V_{Y} l$ & 5'-TACCTACACCAGGAGGGGAAG-3' \\
$V_{\gamma} l l$ & 5'-GGCACTGTCAGAAAGGAATC-3' \\
$V_{\gamma} I I I$ & 5'-TCGACGCAGCATGGGTAAGAC-3' \\
$C \gamma$ & 5'-CATCTGCATCAAGTTGTTATC-3' \\
$\beta_{2} M-f$ & 5'-TACACTGAATTCCACCCCCAC-3' \\
$\beta_{2} M-b$ & 5'-CACTCAATCCAAATGCGGCA-3' \\
\hline
\end{tabular}


Hercules, CA, USA) using the cycling conditions as follows: 15 minutes' initial denaturation at $95^{\circ} \mathrm{C}, 44$ cycles consisted of 30 seconds at $95^{\circ} \mathrm{C}$; 40 seconds at $60^{\circ} \mathrm{C}$; and 2 seconds at $82^{\circ} \mathrm{C}$. The melting curve was obtained from 55 to $95^{\circ} \mathrm{C}\left(0.5^{\circ} \mathrm{C} / \mathrm{s}\right)$. The $2^{(-\Delta \mathrm{CT})}$ method was used to calculate the relative amount of the genes of interest.

\section{Statistical analysis}

The Student's t test or Mann-Whitney $U$ test was performed to compare the means of gene expression levels in different groups. Data were presented as mean \pm SD. Pearson correlation or Spearman's rank correlation analysis was used to estimate the correlations. Statistical analysis was performed using SPSS version 16.0 statistic software package. Differences were considered statistically significant at $P<0.05$.

\section{Results}

VAS scores and serum slgE contents before and after SIT in AR patients

Mean nasal uni-VAS score of 18 AR patients at the beginning of treatment was $7.61 \pm 0.34$, and after immunotherapy for one year significantly decreased to $2.02 \pm$ $0.98(\mathrm{t}=20.772, \mathrm{P}<0.001)$, indicating an alleviation of the nasal hypersensitivity. The mean content of serum sIgE was similar before and after SIT $(22.17 \pm 8.64 \mathrm{kU} / \mathrm{L}$ and $19.72 \pm 7.18 \mathrm{kU} / \mathrm{L}$, respectively; $\mathrm{Z}=1.051, \mathrm{P}=0.278$ ).

\section{Expression pattern of Foxp3 and TCR $V_{\gamma}$ subfamilies in AR} patients and healthy subjects

The expression pattern of TCR Vy subfamily genes was $\mathrm{V} \gamma \mathrm{II}>\mathrm{V} \gamma \mathrm{I}>\mathrm{V} \gamma \mathrm{III}$ in PBMCs from healthy subjects. In contrast, it was $\mathrm{V} \gamma \mathrm{I}>\mathrm{V} \gamma \mathrm{II}>\mathrm{V} \gamma \mathrm{III}$ in AR patients both before and after SIT. Significantly lower expression levels of Foxp3 $(0.20 \pm 0.25), \mathrm{V} \gamma \mathrm{I}(1.02 \pm 0.81), \mathrm{V} \gamma \mathrm{II}(0.99 \pm 0.86)$ and VyIII $(0.39 \pm 0.26)$ were observed in untreated AR patients compared with healthy subjects (Foxp3: $0.37 \pm$ $0.28, Z=-2.253, P=0.024 ; \mathrm{V} \gamma \mathrm{I}: 1.59 \pm 0.89, Z=-2.158$, $P=0.031$; V $\gamma \mathrm{II}: 2.59 \pm 1.28, Z=-3.069, P=0.002$; V $\gamma \mathrm{III}$ : $0.71 \pm 0.19, t=3.345, P=0.003)$. After SIT, the expression levels of $\mathrm{V} \gamma \mathrm{I}$ and $\mathrm{V} \gamma \mathrm{II}$ in AR patients were $1.21 \pm$ 0.48 and $0.96 \pm 0.49$, respectively, not significantly different from those before SIT (V $\gamma \mathrm{I}: t=-0.977, P=0.342$; V $\gamma$ II: $Z=-0.501, P=0.616$, respectively). However, the expression levels of Foxp3 and VyIII were obviously increased after SIT (Foxp3: $0.81 \pm 0.54, t=-0.977, P=0.342$; VүIII: $0.90 \pm 0.69, Z=-0.501, P=0.616$ ) (Figure 1 ).

\section{Correlation analysis of Foxp3 and TCR $\mathrm{V}_{\gamma}$ subfamily genes} There was no significant correlation between the expression levels of Foxp3 and TCR V $\gamma \mathrm{I} \sim$ III genes in healthy subjects $(P=0.533, r=0.224 ; P=0.082, r=-0.576$; $P=0.987, r=0.006$, respectively). Significant positive correlation of the expression levels of Foxp3 and TCR $\mathrm{V} \gamma \mathrm{I} \sim \mathrm{III}$ genes was found before SIT $(P=0.001, r=0.717$; $P=0.017, \quad r=0.553 ; \quad P<0.001, \quad r=0.825$, respectively). After SIT, the expression level of Foxp3 had no significant correlation with those of TCR V $\gamma \mathrm{I}$ or $\mathrm{V} \gamma \mathrm{II}$ genes ( $P=0.932, r=0.022 ; P=0.367, r=0.226)$, but was positively related to the expression level of V $\gamma$ III gene $(P=0.014$, $r=0.567$ ) (Figure 2).

\section{Correlation analysis of VAS score, Foxp3 and TCR V $\gamma$ subfamily genes}

In AR patients before SIT, significant negative correlation was observed between the VAS score and the expression level of Foxp3 $(P=0.002, \quad r=-0.684)$, and between the VAS score and the expression level of TCR V YIII $(P=0.044, r=-0.480)$. After SIT for one year, with the expression level of Foxp3 gene increasing and TCR

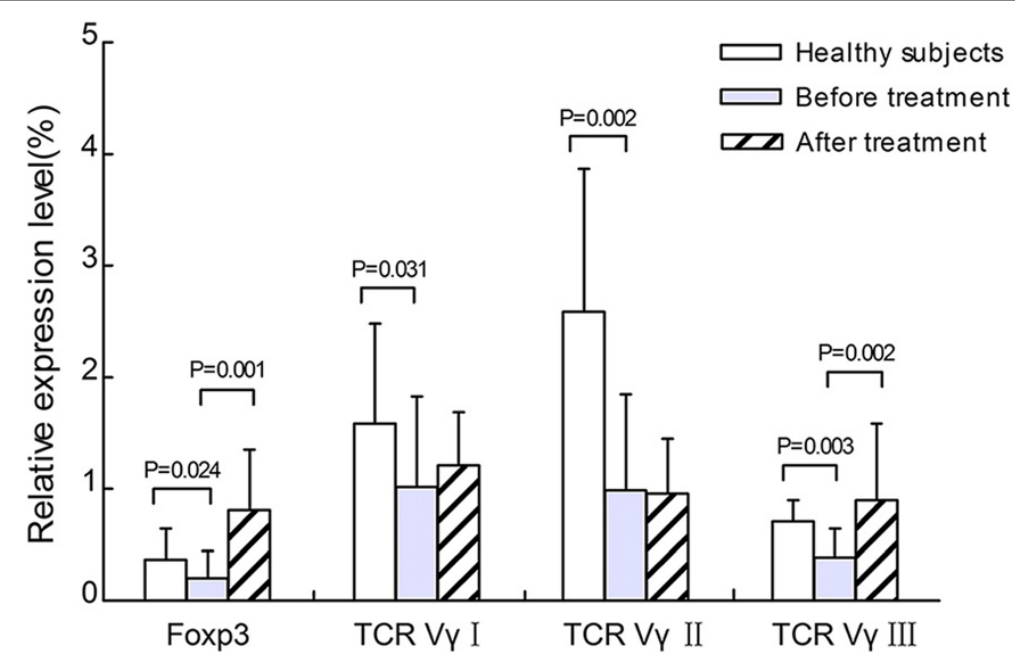

Figure 1 The relative expression levels of Foxp3 and TCR $V_{Y}$ subfamilies before and after SIT. 


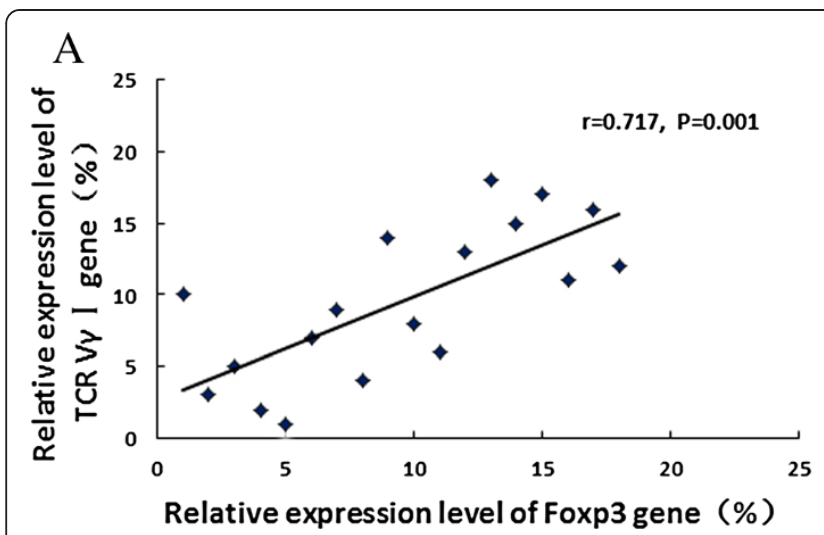

C

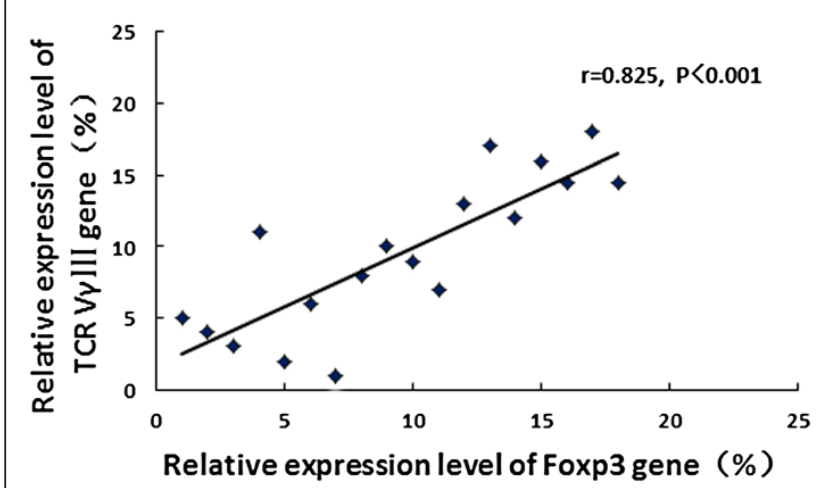

B

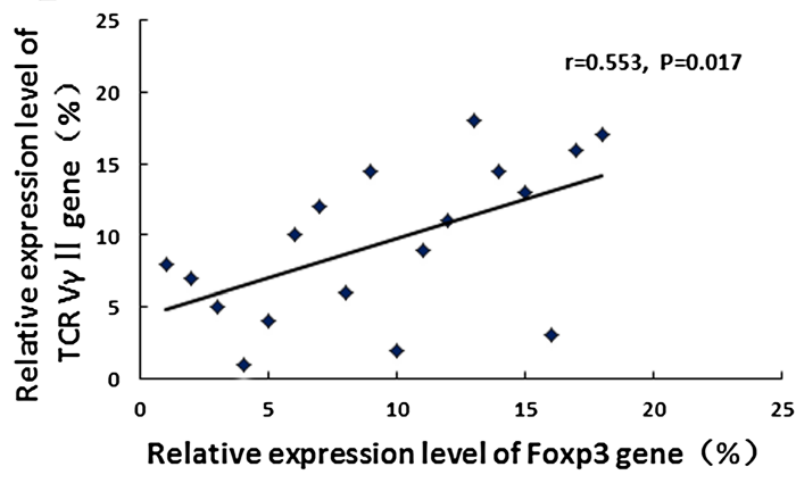

D

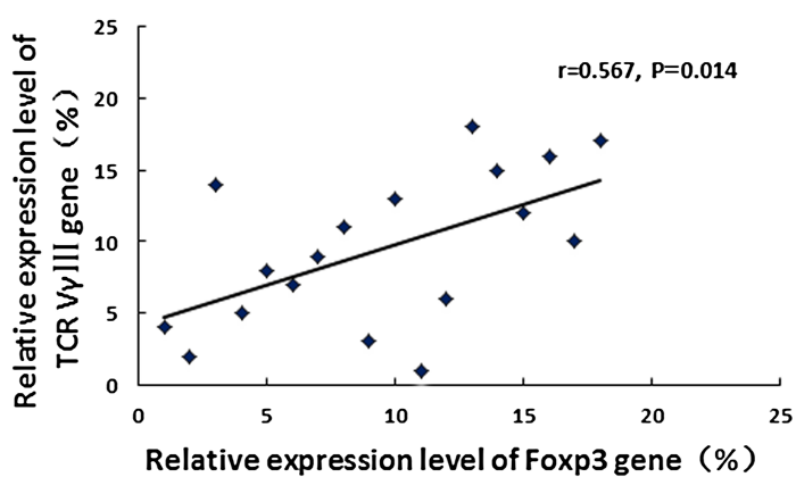

Figure 2 Correlations between Foxp3 and TCR $V_{\boldsymbol{V}}$ gene expression levels before and after SIT. (A) Foxp3 Vs. TCR VYl in the before SIT group; (B) Foxp3 vs. TCR VYll in the before SIT group; (C) Foxp3 vs. TCR VyIII in the before SIT group; (D) Foxp3 vs. TCR VYIII in the after SIT group. Significant positive correlations were indicated.

VyIII decreasing, significant negative correlations remained between the levels of these two genes and the VAS score $(P<0.001, \quad r=-0.737 ; \quad P=0.017, \quad r=-0.556$, respectively) (Figure 3).

\section{Correlation analysis of Foxp3, TCR $V_{\gamma}$ subfamily genes, VAS score and sigE levels}

No significant correlation was shown between the expression levels of Foxp3, TCR V $\gamma$ subfamily genes, VAS score and the contents of serum sIgE in AR patients before or after SIT for one year. (Before SIT: $P=0.763, r=-0.076$; $P=0.711, \quad r=-0.094 ; P=0.720, \quad r=-0.091 ; P=0.750$, $r=0.081 ; P=0.943, r=0.018$, respectively. After SIT: $P=0.403, r=-0.210 ; P=0.380, r=-0.220 ; P=0.556, r=0.149$; $P=0.475, r=-0.180 ; P=0.657, r=0.112$, respectively).

\section{Discussion}

SIT could restore the body's immune tolerance and also rectify the body's immune imbalance, making it the only etiological therapy for allergic diseases at present [13]. Though SIT has been practiced for more than a hundred years, and its safety and effectiveness have been confirmed with the implement of standardized allergen vaccines, it has not been well clarified regarding its role during the course of therapy. AR is a kind of type I allergic disease primarily mediated by IgE. Serum sIgE level is the important clinical criteria to diagnose AR, and is supposed to decline in patients under effective SIT. However, recent studies have shown that serum sIgE level increased but not decreased in the early stage of SIT, and a long therapeutic process was required to observe the reduction in $\operatorname{SIgE}[14,15]$. Similar results were found in our study, which showed that the serum sIgE level after one-year-long SIT was similar to that before SIT. Moreover, there was no significant correlation between sIgE level and VAS score. These data suggest that serum sIgE level has no linear correlation with the improvement of clinical symptoms in the early stage of SIT, thus it cannot serve as an objective criteria to evaluate the effectiveness of SIT. We speculate that patients with AR cannot be isolated from house dust mite antigen, which may result in the continued existence of allergic humoral immunity and continuous generation of sIgE during early SIT. Consequently, the improvement of nasal symptoms in the early stage of SIT is likely to benefit from the cellular immunity mediated by $\mathrm{T}$ cells. 

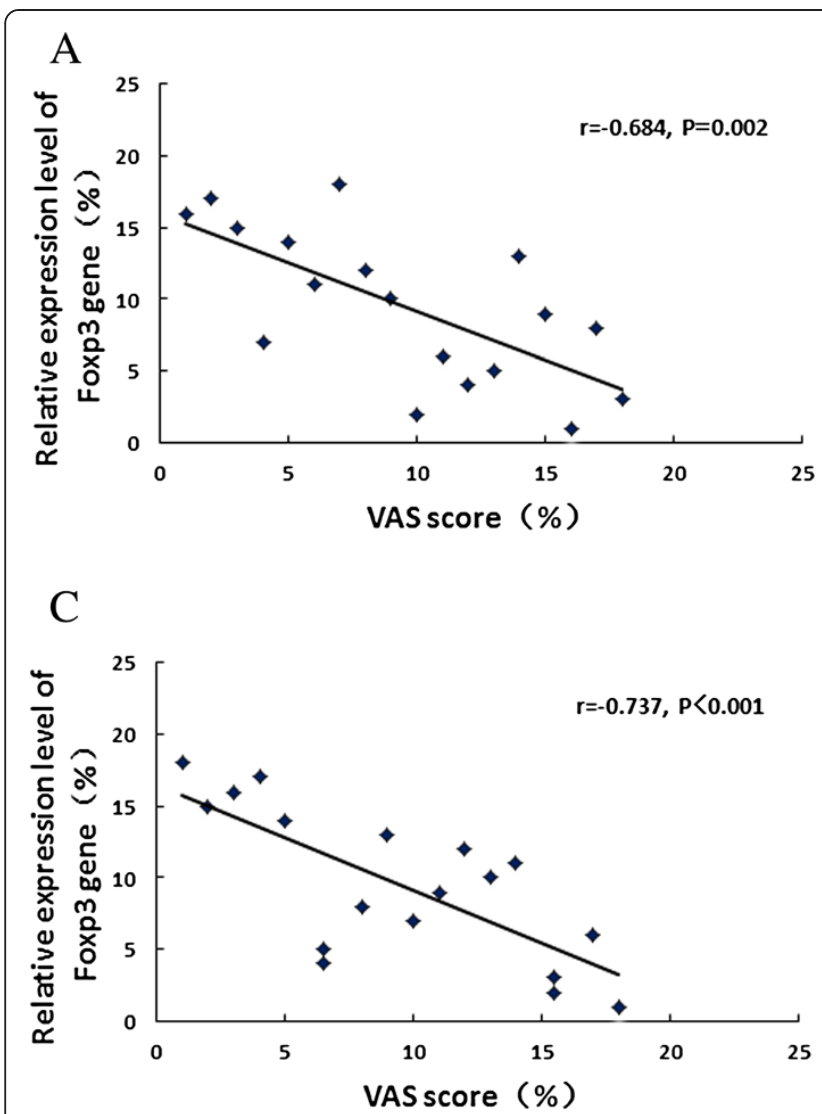

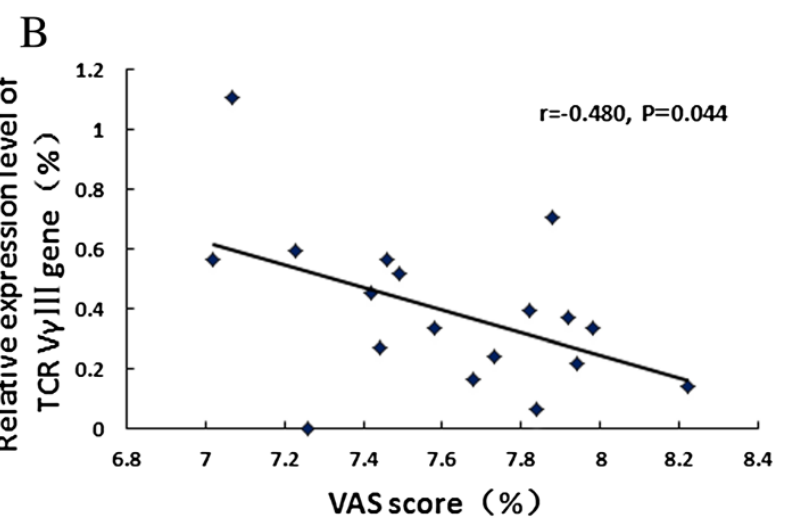

$\mathrm{D}$

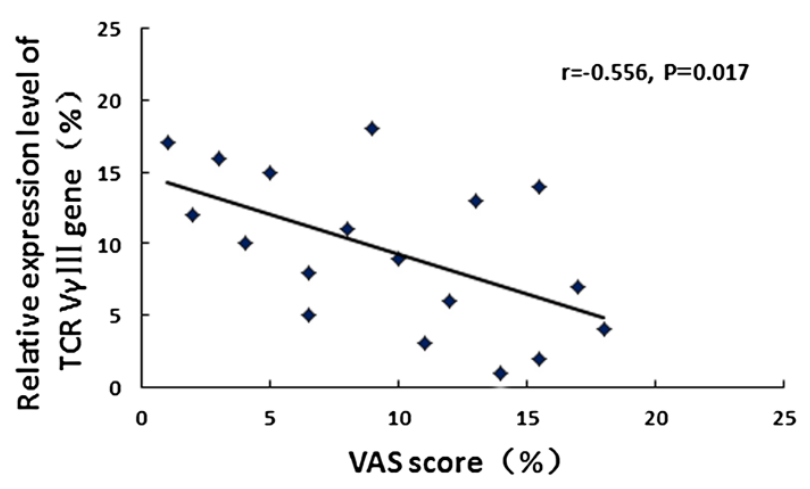

Figure 3 Correlations between VAS score, Foxp3 and TCR V $\gamma$ gene expression levels before and after SIT. (A) VAS VS. Foxp3 in the before SIT group; (B) VAS vS. TCR VYIII in the before SIT group; (C) VAS Vs. Foxp3 in the after SIT group; (D) VAS VS. TCR VYIII in the after SIT group. Significant negative correlations were indicated.

$\mathrm{CD} 4{ }^{+} \mathrm{CD} 25^{+}$Treg was first discovered by Japanese scholar Sakaguchi in 1995 and was demonstrated to act as a vital immune modulator to maintain body's immune homeostasis [16]. Studies have shown that $\mathrm{CD} 4{ }^{+} \mathrm{CD} 25^{+}$ Treg can inhibit excessive type I hypersensitivity mainly through its related cytokines IL-10 and TGF- $\beta$. Forkhead box p3 (Foxp3), a specific transcription factor of Treg, plays an essential role in Treg's development and function. The mRNA expression level of Foxp3 can directly reflect Treg's quantity and functional status in vivo [17]. It has been verified that Foxp $3^{+}$Treg quantity and/or function decrease in the peripheral blood of patients with respiratory allergy, and recover after immunotherapy $[2,18]$. This study showed that Foxp3 mRNA expression level in PBMCs was significantly lower in the AR patients group than in the control group, suggesting a reduction of Treg quantity thus a hindered immunosuppressive function in AR. In contrast, in AR patients after SIT for one year, Foxp3 mRNA expression level significantly increased, suggesting the rectification of Treg quantity and/or function. In addition, with Foxp3 mRNA expression level ascending and VAS score descending, a significant negative correlation between them was maintained before and after SIT. These results suggest that Treg may play a pivotal role in the inhibition of patients' symptoms caused by allergic inflammation.

The $\gamma \delta \mathrm{T}$ cells mainly distribute in the skin, small intestine, lung, and reproductive organs, and engage in the mucosal immune processes. Respiratory mucosal immunological barrier imbalance contributes largely to the occurrence of AR and asthma, and the role of $\gamma \delta$ T cells play in these allergic diseases has received more attention [19]. It was reported that $\gamma \delta \mathrm{T}$ cells presented dualdirectional regulatory function under different conditions via secreting diverse cytokines, which regulated what functional subsets $\gamma \delta$ T cells were divided into [20]. For instance, $\gamma \delta$ T cells showed a Th1 effect by generating IL-2 and INF- $\gamma$ when bacterial infection occurred inside cells; but showed a Th2 effect by stimulating B cells with IL-4 and IL-5 with extracellular parasite infection. Additionally, human $\gamma \delta$ T cells can be divided into several subsets based on different combinations of $\mathrm{V} \gamma$ and $\mathrm{V} \delta$ chains at the variable regions of the $\mathrm{T}$ cell receptors. Among them, $\mathrm{V} \gamma \mathrm{I}$ subsets consist of $\mathrm{V}_{\gamma} 2,3,4,5$ and $8, \mathrm{~V} \gamma \mathrm{II}$ subsets contain $\mathrm{V} \gamma$, and $\mathrm{V} \gamma \mathrm{III}$ subsets include $\mathrm{V} \gamma 10$ [21]. In animals, $\mathrm{V} \gamma 1^{+} \gamma \delta \mathrm{T}$ subsets could aggravate airway 
hyperresponsiveness (AHR), acting as pro-inflammatory

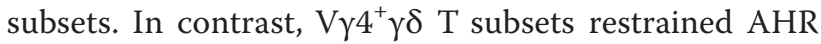
and had a protective effect on airway mucosa, belonging to anti-inflammation subsets $[3,6]$. Though there are differences in the distribution of $\gamma \delta$ T cell subsets between humans and animals and between different organs, it is affirmed that $\gamma \delta$ T cells contain both pro- and anti-inflammation subsets. The aim of this study was to determine the functional subsets that each $\mathrm{V} \gamma \mathrm{I} \sim \mathrm{III}$ subfamilies belong to by testing the gene expression levels of $\mathrm{V} \gamma \mathrm{I} \sim \mathrm{III}$ in PBMCs from AR patients before and after SIT. Our results showed that $\mathrm{V} Y \mathrm{I} \sim \mathrm{III}$ expression levels in PBMCs from AR patients before SIT were all significantly lower than those in healthy controls, and V VIII expression level was negatively correlated to VAS score. After SIT for one year, changes in $\mathrm{V} \gamma \mathrm{I}$ and $\mathrm{V} \gamma \mathrm{II}$ expression levels in PBMCs had no statistical significance compared with those before SIT, while VyIII expression level significantly increased and was negatively correlated with VAS score. These results suggest that $\mathrm{V}_{\gamma}$ subfamilies, especially $\mathrm{V} \gamma \mathrm{III}$, were closely related to the occurrence of AR. In addition, V $\gamma$ III subfamily might play an anti-inflammation role in the early stage of SIT, thereby alleviating clinical symptoms of AR patients.

In some immunological diseases, $\gamma \delta \mathrm{T}$ cells were found to influence the differentiation and function of Treg via secreting plenty of INF- $\gamma$, IL-17 or other cytokines for local inflammation [6,22]. Nevertheless, it has not yet been reported which subfamilies of $\gamma \delta$ T cells are related to Treg in AR and SIT. This study showed that the expression levels of both $\mathrm{V} \gamma \mathrm{I}$ and $\mathrm{V} \gamma \mathrm{II}$ subfamily genes in PBMCs were positively related to that of Foxp3 gene, and the expression level of VyIII subfamily gene was positively related to that of Foxp3 gene both before and after SIT. These results strongly suggest that there exists a mutual regulatory effect and some dynamic equilibrium between Treg and TCR $V_{\gamma}$ subfamilies, especially V $\gamma$ III, in AR and the early stage of SIT. Future studies with larger sample size will further confirm the dynamic equilibrium between Treg and $\gamma \delta \mathrm{T}$ cells in peripheral blood as well as in nasal mucosa of AR patients before and after SIT.

\section{Conclusions}

We characterized the expression pattern of Foxp3 gene and three TCR VY subfamily genes as well as the potential correlation between them in the PBMCs of AR patients before and after one-year-long effective SIT. The results showed that Treg and $\mathrm{V}_{\gamma}$ subfamily $\mathrm{T}$ cells were in a dynamic equilibrium in AR patients before and after effective immunotherapy for one year. The early improvement of symptoms following immunotherapy might be independent of the serum sIgE content in AR patients, but associated with the reconstitution of $\mathrm{T}$ cell immunity.
Competing interests

The authors declare that they have no competing interests.

\section{Authors' contributions}

RZ and XLW coordinated the study, performed the real-time PCR and helped draft the manuscript; XKH and YLC prepared RNA and performed the serum test; YQL and GHZ helped to analyze data; QTY contributed to the concept development and study design. All authors read and approved the final manuscript.

\section{Acknowledgements}

The study was supported by grants from National Natural Science Foundation of China (No. 81371072, 81200388), Guangdong Natural Science Foundation (No. S2013010016386), the Science and Technology Planning Project of Guangdong Province of China (No. 2012B031800403), and a project of the Zhujiang Science \& Technology Star of Guangzhou City (No. 2013027).

\section{Author details}

${ }^{1}$ Department of Otorhinolaryngology-Head and Neck Surgery, The Third Affiliated Hospital, SUN Yat-sen University, Guangzhou 510630, China. ${ }^{2}$ Institute of Hematology, Medical College, Jinan University, Guangzhou 510632, China

Received: 22 November 2013 Accepted: 20 January 2014 Published: 25 January 2014

\section{References}

1. Nouri-Aria KT: Foxp3 expressing regulatory T-cells in allergic disease. Adv Exp Med Biol 2009, 665:180-194.

2. Kay AB: Allergy and allergic diseases. Second of two parts. N Engl J Med 2001, 344:109-113.

3. Cook L, Miyahara N, Jin N, Wands J, Taube C, Roark CL, Potter TA, Gelfand EW, O'Brien RL, Born WK: Evidence that CD8+ dendritic cells enable the development of $\gamma \delta \mathrm{T}$ cells that modulate airway hyperresponsiveness. $\mathrm{J}$ Immunol 2008, 181:309-319.

4. Yang Q, Li P, Li Y, Wu X, Huang X, Chen Y, Zhang G: Effects of immunotherapy on the distribution and clonality of TCR $V_{Y}$ and $V \delta$ subfamily T cells in allergic rhinitis patients. J Med Biochem 2012, 31:94-99.

5. Korematsu S, Tanaka Y, Nagakura T, Minato N, Izumi T: Human gammadelta $\mathrm{T}$ cells modulate the mite allergen-specific T-helper type 2-skewed immunity. Clin Exp Allergy 2007, 37:1681-1687.

6. Petermann F, Rothhammer V, Claussen MC, Haas JD, Blanco LR, Heink S, Prinz I, Hemmer B, Kuchroo VK, Oukka M, Korn T: Gammadelta T cells enhance autoimmunity by restraining regulatory $T$ cell responses via an interleukin-23-dependent mechanism. Immunity 2010, 33:351-363.

7. Bousquet J, Khaltaev N, Cruz A, Denburg J, Fokkens W, Togias A, Zuberbier T, Baena-Cagnani C, Canonica G, van Weel C: World health organization; GA (2) LEN; AllerGen. allergic rhinitis and its impact on asthma (ARIA) 2008 update (in collaboration with the world health organization, GA (2) LEN and AllerGen). Allergy 2008, 63:8-160.

8. Mailing HJ: Immunotherapy as an effective tool in allergy treatment. Allergy 1998, 53:461-472.

9. Chen S, Zha X, Yang L, Li B, Liye Z, Li Y: Deficiency of CD3gamma, delta, epsilon, and zeta expression in T cells from AML patients. Hematology 2011, 16:31-36.

10. Bousquet P, Combescure C, Neukirch F, Klossek J, Mechin H, Daures JP, Bousquet J: Visual analog scales can assess the severity of rhinitis graded according to ARIA guidelines. Allergy 2007, 62:367-372.

11. Xuan L, Wu X, Zhang Y, Fan Z, Ling Y, Huang F, Zhang F, Zhai X, Liu Q: Granulocyte colony-stimulating factor affects the distribution and clonality of TRGV and TRDV repertoire of T cells and graft-versus-host disease. J Transl Med 2011, 9:215.

12. Li B, Liu S, Niu Y, Fang S, Wu X, Yu Z, Chen S, Yang L, Li Y: Altered expression of the TCR signaling related genes CD3 and FcepsilonRlgamma in patients with aplastic anemia. $J$ Hematol Oncol 2012, 5:6.

13. Spector S, Wallace D, Nicklas R, Portnoy J, Blessing-Moore J, Bernstein D, Cox L, Oppenheimer J, Lang D, Schuller D: Comments on allergic rhinitis 
and its impact on asthma (ARIA) guidelines. J Allergy Clin Immunol 2011, 127:1641-1642.

14. Akdis CA, Akdis M: Mechanisms of allergen-specific immunotherapy. J Allergy Clin Immunol 2011, 127:18-27.

15. Burks A, Calderon MA, Casale T, Cox L, Demoly P, Jutel M, Nelson H, Akdis CA: Update on allergy immunotherapy: American Academy of Allergy, Asthma \& Immunology/European Academy of Allergy and Clinical Immunology/PRACTALL consensus report. J Allergy Clin Immunol 2013, 131:1288-1296.

16. Sakaguchi S, Sakaguchi N, Asano M, Itoh M, Toda M: Immunologic selftolerance maintained by activated T cells expressing IL-2 receptor alpha-chains (CD25). Breakdown of a single mechanism of self-tolerance causes various autoimmune diseases. J Immunol 1995, 155:1151-1164.

17. Hori S, Nomura T, Sakaguchi S: Control of regulatory T cell development by the transcription factor Foxp3. Science 2003, 299:1057-1061.

18. Provoost S, Maes T, van Durme YM, Gevaert P, Bachert C, Schmidt-Weber CB, Brusselle GG, Joos GF, Tournoy KG: Decreased FOXP3 protein expression in patients with asthma. Allergy 2009, 64:1539-1546.

19. Takai T, Ikeda S: Barrier dysfunction caused by environmental proteases in the pathogenesis of allergic diseases. Allergol Int 2011, 60:25-35.

20. Szczepanik M, Nowak B, Askenase P, Ptak W: Cross-talk between gammadelta T lymphocytes and immune cells in humoral response. Immunology 1998, 95:612.

21. Beetz S, Wesch D, Marischen L, Welte S, Oberg HH, Kabelitz D: Innate immune functions of human gammadelta T cells. Immunobiology 2008, 213:173-182.

22. Cai Y, Shen X, Ding C, Qi C, Li K, Li X, Jala VR, Zhang H-G, Wang T, Zheng J: Pivotal role of dermal IL-17-producing $\gamma \delta \mathrm{T}$ cells in skin inflammation Immunity 2011, 35:596-610.

doi:10.1186/1479-5876-12-24

Cite this article as: Zheng et al:: Gene expression pattern of Treg and TCR VY subfamily T cells before and after specific immunotherapy in allergic rhinitis. Journal of Translational Medicine 2014 12:24.

\section{Submit your next manuscript to BioMed Central and take full advantage of:}

- Convenient online submission

- Thorough peer review

- No space constraints or color figure charges

- Immediate publication on acceptance

- Inclusion in PubMed, CAS, Scopus and Google Scholar

- Research which is freely available for redistribution 